\title{
Factors Mediating between Employee Strategy Awareness and Commitment to Organizational Success
}

\author{
Deborah A. Gagnon ${ }^{1}$, Gregory M. Moore ${ }^{2} \&$ Gehan D. Shanmuganathan ${ }^{3}$ \\ ${ }^{1}$ Department of Psychology, Wells College, Aurora, New York, USA \\ ${ }^{2}$ Department of Mathematics, Wells College, Aurora, New York USA \\ ${ }^{3}$ Center for Business and Entrepreneurship, Wells College, Aurora, New York, USA \\ Correspondence: Gehan D. Shanmuganathan, Center for Business and Entrepreneurship, Wells College, Aurora, \\ New York 13026, USA. Tel: 1-315-364-3307. E-mail: gshanmuganathan@wells.edu
}

Received: August 9, 2014

Accepted: September 17, 2014 Online Published: November 26, 2014

doi:10.5539/jms.v4n4p24

URL: http://dx.doi.org/10.5539/jms.v4n4p24

\begin{abstract}
This study tested a theoretical model that includes seven factors hypothesized to mediate between employee organizational strategy awareness and commitment.The mediating factors include diffusion and innovation, social exchange, economic exchange relationship, job satisfaction, knowledge sharing and satisfaction, trust, and person-organization fit. Employees $(n=130)$ drawn from all organizational levels in 12 business sectors (financial, manufacturing, aviation, distribution, healthcare, mining, agriculture, consumer goods, technology, telecommunications, oil and gas, education) were surveyed to measure organizational strategy awareness, organizational commitment, and values on the seven mediating factors. Structural Equation Modelling (SEM) supported a positive fit of data to model. Linear regression analysis revealed that excluding diffusion of innovation, all other mediating variables established a positive correlation with employee commitment supporting the overall model. However, we believe that the model is over-fitting the data given the large number of variables and small number of data points. These results show promise, but require further investigation which we propose for a second phase of the investigation. Understanding the factors that mediate between employee strategy awareness and organizational awareness should be of interest and value to managers who can, in turn, focus on developing those mediating factors that could ultimately improve organizational success.
\end{abstract}

Keywords: employee commitment, organizational strategy awareness, economic exchange, job satisfaction, knowledge sharing, person-organization fit, diffusion of innovation, trust, social exchange

\section{Introduction}

The relationship between employee commitment to an organization and organizational success has often been described as a social exchange process (e.g., Chao, Yu, Cheng, \& Chuang, 2013). We propose that in many industries, organizational strategy awareness plays an antecedent role in influencing employee commitment level and that several factors may play a role in mediating between employee awareness of organizational strategy and employee commitment to organizational success. Therefore, this study sought to examine the relationship between two key variables - organizational strategy awareness and organizational commitment - and the factors that mediate between them.To date, scholars have argued formediating variables such as job demands and resources, employee motivation, social exchange, economic exchange, transaction cost, conservation of resources, and diffusion of innovation (Chang, Rosen, \& Levy, 2009; Chao, Yu, Cheng, \& Chuang, 2013; Peng \& Chiu, 2010; Tyler \& Gnyawali, 2009). These study findings have played a pivotal role in the body of current literature on the subject. Surprisingly, however, we found no theoretical grounding to describe the relationship between the awareness of organizational strategy and employee commitment in relation to organizational success. This paper proposes such a model capturing the relationship between awareness and commitment and the factors that mediate them, and describes preliminary findings that support the theoretical model. Current literature already explains the relationship between the employee and the organization that influences employee commitment in achieving organizational goals (Bartek, 2009; Peng \& Chiu, 2010; Tyler \& Gnyawali, 2009). The theory proposed in this paper takes an antecedent factor-employee awareness level of organizational strategy - and explains how key variables such as diffusion of innovation, social exchange, economic exchange, job satisfaction, knowledge sharing and satisfaction, trust, and person organization fit would operate as 
mediating variables between that awareness and employee commitment for organizational success. Therefore, this paper adds an extension of current theory and describes research that tests the resulting model. It presents a new understanding of the relationship between employee awareness of organizational strategy and commitment which not only adds to the current scholarship in the area but has practical application to organizational management, with the end goal of improving organizational success.

\section{Theoretical Model}

A description of the seven hypothesized mediating factors, as well as employee commitment and strategy awareness, are described and defined.

\subsection{Diffusion of Innovation (DOI)}

This theory seeks to explain how, why, and at what rate new ideas and technology spread through cultures (Miller \& Amos, 2007). The five most important characteristics for an innovation to have in order to be adopted include: relative advantage, compatibility, complexity, trial ability, and observability (Bartek, 2009). In other words, an innovation must seem to have an advantage over existing methods and must be compatible with the systems and culture already in place, easy enough to use, testable before committing to regular use, and observed in use by other people.

\subsection{Social Exchange (SE)}

Social Exchange Theory is based on the notion that people exchange knowledge with those with whom they have a reciprocal relationship. Therefore, people are more likely to share knowledge with those who also share knowledge with them (Aryee, Walumbwa, Zhou, \& Hartnell, 2012; Canessa et al., 2012; Kexin, Zhengxue et al., 2013). It exchanges non-material goods between individuals in relationships. These non-material goods might include affection, prestige, power, or in this case, knowledge (Shin, Taylor, \& Seo, 2012). Ideally, there is a balance in this exchange, with both parties receiving an equal share of non-material goods.

\subsection{Economic Exchange Relationship (EER)}

The emphasis of this theory is short-term and involves the exchange of concrete or economic resources in a quid pro quo fashion (Chen, 2009). Economic exchange reflects the exchange of tangible resources over a finite period or a discrete transition (Zhu, 2012). The fulfillment of an economic exchange is vital to the continuation of the employee-organization relationship. Further, it contends that people behave based on a benefits set (Nakonezny \& Denton, 2008). Bargaining and negotiations are components of economic exchange theory.

\subsection{Job Satisfaction (JS)}

This is an enduring construct in individual-level organizational research. It has often been thought of as an emotional state resulting from the evaluation or appraisal of one's job experiences or as a psychological state simultaneously represented by cognitive and affective indicators (Alarcon \& Lyons, 2011; De Cuyper, Van der Heijden, \& De Witte, 2011; Zhu, 2012). Job satisfaction has been defined as a pleasurable emotional state resulting from the appraisal of one's job, an affective reaction to one's job, and an attitude towards one's job (Hakanen, Schaufeli, \& Ahola, 2008).

\subsection{Knowledge Sharing and Satisfaction (KSS)}

At the individual level, previous studies have found that psychological factors such as trust, attitudes, and norms have a significant impact on knowledge-sharing intention and behavior (Chen, 2011; Liao, 2006; Wu, 2013). The sources of knowledge sharing and satisfaction is most likely composed of individual and environmental factors, for example, the expectation of returns after knowledge sharing, or a good knowledge-sharing environment in which employees feel free to exchange knowledge during work and social activities (Wu, 2013).

\subsection{Person-Organization Fit (POF)}

This concept is an antecedent to Employee Commitment. High Person-Organizational Fit means that personal goals and values are congruent with organizational goals and values.Prior research has suggested that there is a positive relationship between Person-Organizational fit and organizational commitment (Chang, Rosen, \& Levy, 2009; De Cuyper, Van der Heijden, \& De Witte, 2011). Person-Organizational Fit should promote employees' organizational commitment.

\subsection{Trust (T)}

Trust is a critical constructive element in human relationships. This construct plays a vital role in influencing employee commitment to the organization (Chao, Yu, Cheng, \& Chuang, 2013). Trust is a personality phenomenon that drives one to build and foster meaningful relations to achieve mutually agreed upon goals. 
Employees who are distrustful are a question mark in relation to organizational loyalty and vice versa. Current literature explains how trust works as a predictor and mediator of commitment for organizational success (Jang, 2013). Often times, trust causes one to overlook risks of being taken advantage of and to act for collective gains. Trust can be defined as the belief that dreams and expectations that are dependent on others can nonetheless be achieved.

\subsection{Employee Commitment (EC)}

Organizational commitment is defined as the relative strength of an individual's identification with and involvement in an organization (De Cuyper, Van der Heijden, \& De Witte, 2011; Peng \& Chiu, 2010; Taris \& Schreurs, 2009). There are two types of employee commitments: normative commitment to change - defined as support for change stemming from employees' sense of obligation to their organization - and affective commitment to change - defined as a desire to support change based on beliefs about the benefits it brings (Liao, 2006; Peng \& Chiu, 2010; Sharma, Borna, \& Stearns, 2009; Shin, Taylor, \&Seo, 2012). Some scholars define relational commitment as existing when an exchange partner believes that an ongoing relationship with another is sufficiently important to warrant maximum efforts at maintaining the relationship (Liao, 2006; Sharma, Borna, \& Stearns, 2009). Commitment infers an enduring desire and willingness to work in order to maintain the relationship between parties in a specific context (Chang, Rosen, \& Levy, 2009).

\subsection{Organizational Strategy Awareness (OSA)}

Organizations develop and deploy mainly three types of strategies. These strategies are organizational, business, and operational strategy (Altman, 2009; Jimena, 2009). The focus of organizational strategy is to set the direction of the organization for the future in relation to environmental changes. Business strategy focuses on how to compete in respective markets. Operational strategy plays a supportive role to implement organizational and business level strategies (Anderson \& Anderson, 2009). Effective strategies should be innovative, support strategic advantage, deliver value to all the stakeholders, and be unique (Asser \& Hodges, 2009).

Based on the above factors, the following theoretical framework (see Figure 1) and hypotheses are proposed:

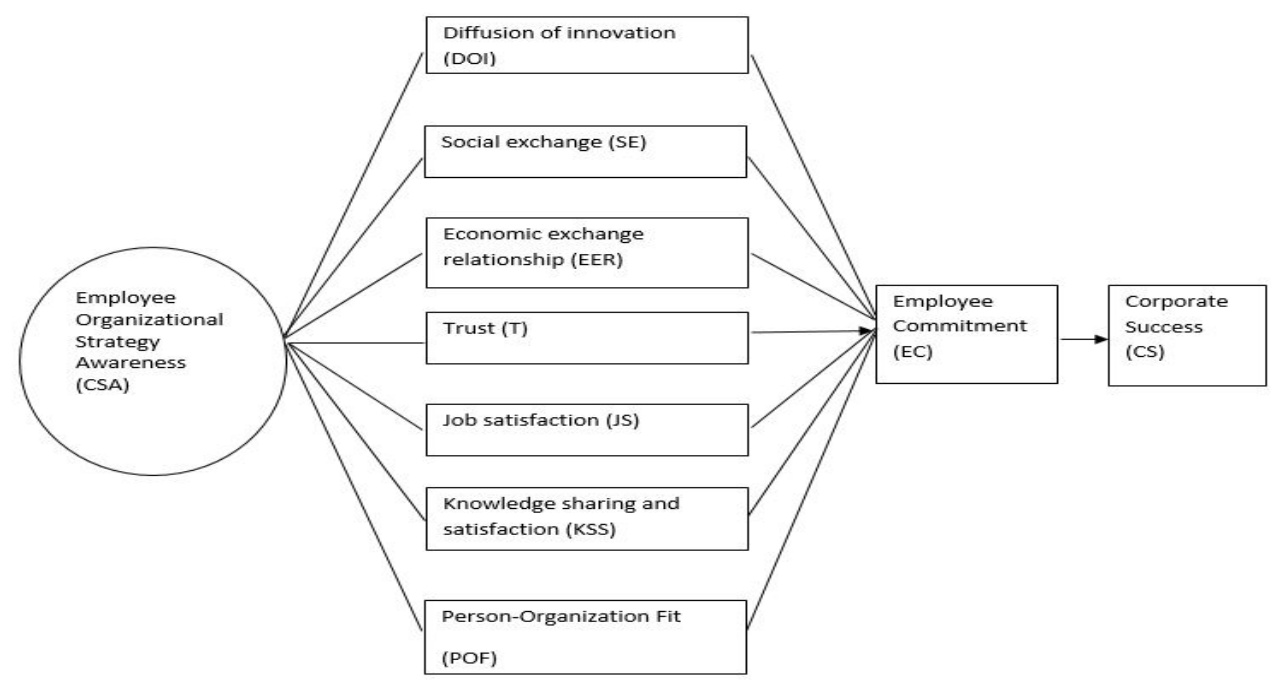

Figure 1. Theoretical model

\section{Hypotheses}

\subsection{Mediation of Diffusion of Innovation on the Relationship between OSA and EC}

Organizations typically use all possible communication channels to make their employees aware oforganizational strategies with the objective of inducing employees' commitment level to achieve organization goals (Bartek, 2009). However, prior studies have argued that employee commitment levels oftentimes falter merely for lack of awareness of organizational strategy (Miller \& Amos, 2007). Level of employee commitment depends on how, when, and at what rate strategy information permeates through an organization. Such research offers empirical support for our expectation that diffusion of innovation functions as a mediating variable on the relationship between organizational strategy awareness and employee commitment (Bartek, 2009). Building on this premise, we expect the following: 
Hypothesis 1: Diffusion of innovation will mediate the positive relationship between employee organizational strategy awareness and employee commitment towardorganizational success.

\subsection{Mediation of Social Exchange on the Relationship between OSA and EC}

Social exchange theory is supported by empirical evidence thatdemonstrates employees share non-material goods between individuals in relationships. Employees tend to share affection, prestige, power or, in this case, knowledge withcolleagues who likewise share with them in their respective subgroups (Aryee et al., 2012; Canessa et al., 2012; Kexin, Zhengxue et al., 2013). On the basis of this empirical evidence, we propose the following:

Hypothesis 2: Social exchange will mediate the positive relationship between employee organizational strategy awareness and employee commitment for organizational success.

\subsection{Mediation of Economic Exchange on the Relationship between OSA and EC}

Employees motivate themselves with a predetermined benefit at the end of their behavior (effort) in any organization. More specifically, some employees are motivated based on economic benefits (Chen, 2009). This phenomenon is apparent especially, at the operational level, where employees seek short term economic benefits in exchange for committing themselves to the success of the organization. Past studies confirm that employees depend on economic exchange that is attached to their performance (Nakonezny \& Denton, 2008). Employees who are directly involved with sales in organizations are legitimately attached to short term economic benefits in order to induce their level of commitment in achieving sales quotas (Nakonezny \& Denton, 2008). However, employees who are not directly related to sales functionsmay still be motivated if they are given some economic benefits for their organizational efforts in line with organizational success. Further, there is empirically supported evidence to argue that economic exchange relationship directly influences employee commitment (Zhu, 2012). Therefore, we propose the following:

Hypothesis 3: Economic exchange will mediate the positive relationship between employee organizational strategy awareness and employee commitment for organizational success.

\subsection{Mediation of Trust on the Relationship between OSA and EC}

Trust is an important psychological construct for employee-employer relationship. Employees sacrifice certain things (time, money, engagement, and entertainment) in life based on the notion of trust. Trust is one of the key factors that drives organizational success, according to many scholars (e.g., Jang, 2013). When there is a low level of trust between the two parties (employee and employer), often times not only does employee productivity level decrease, but employees then also tend to work for their own benefits rather than the organization's (Chao, Yu, Cheng, \& Chuang, 2013).However, nobody has heretofore proposed that employee organizational strategy awareness directly influences employee commitment with the mediation of trust factor. This expectation is formally captured in the following hypothesis;

Hypothesis 4: Trust will mediate the positive relationship between employee organizational strategy awareness and employee commitment for organizational success.

\subsection{Mediation of Job Satisfaction on the Relationship between OSA and EC}

This is a personal psychological temperament that derives from one's own performance. It has been argued that as employees increase their level of commitment in order to achieve organizational goals, a higher level of job satisfaction is achieved (Hakanen, Schaufeli, \& Ahola, 2008). However, there is currently no scholarly work to suggest that job satisfaction functions as a mediating variable in the relationship between organizational strategy awareness and employee commitment. Thus we propose:

Hypothesis 5: Job satisfaction will mediate the positive relationship between employee organizational strategy awareness and employee commitment for organizational success.

\subsection{Mediation of Knowledge Sharing and Satisfaction on the Relationship between OSA and EC}

Knowledge sharing related to market, product, and organization has led to increases inemployee self-satisfaction (Chen, 2011; Liao, 2006; Wu, 2013). Employees tend to share knowledge with the employees who likewise share with them in their respective subgroups. Collectively, if the acquired knowledge is used to maintain overall organizational competitive advantage, these respective organizations would achieve organizational success (profitability), which is a financial benefit. In the same vein, the acquired knowledge of the employees will increase their level of efficiency $(\mathrm{Wu}, 2013)$. However, this has been a rare observation in current literature. Therefore, there is a lack of empirical evidence in the current literature to support that knowledge sharing and 
satisfaction functions as a mediating variable on the relationships between OSA and EC. Thus, we propose to test the following:

Hypothesis 6: Knowledge sharing and satisfaction will mediate the positive relationship between employee organizational strategy awareness and employee commitment for organizational success.

\subsection{Mediation of Person-Organization Fit on the Relationship between OSA and EC}

Long-term employment agreements deliver benefits to both employee and employer parties (De Cuyper, Van der Heijden, \& De Witte, 2011; Peng \& Chiu, 2010; Taris \& Schreurs, 2009). Changes in the business environment and recent dynamics in the labor market such as layoffs, increase of unemployment rate, and other factors has affected such agreements. However, such agreements could be expected to leverage the employee-employer relationshipby improving understanding of the organization and the employee as a responsibility of each party: It is the organization's responsibility to assess if the employee fits into the organizational culture, whereas it is the employee's responsibility to assess if his own culture fits into the organizational culture (Chang, Rosen, \& Levy, 2009; De Cuyper, Van der Heijden, \& De Witte, 2011). The literature does not currently support any arguments to validate a mediation of person-organization fit the relationship between OSA and EC. This expectation is formally captured in the following hypothesis:

Hypothesis 7: Person organization fit will mediate the positive relationship between employee organizational strategy awareness and employee commitment for organizational success.

\subsection{Employee Organizational Strategy Awareness and Employee Commitment}

One of the key factors for organizational success is the degree of employee commitment level and organizations typically make every effort to increase employees' commitment level with the objective of achieving organization success (Anderson \& Anderson, 2009). However, we believe employees will not commit to organizational success unless they have an appropriate understanding of the organizational strategy. Therefore, the leaders in organizations must invest time and resources to communicate organizational strategies to their employees. Based on this notion, we propose the following hypothesis:

Hypothesis 8: Employees' organizational strategy awareness has a positive relationship with employees' commitment for organizational success.

\section{Methodology}

\subsection{Sample}

This quantitative study administered an online survey to 152 respondents from within all organizational levels in 12 business sectors: financial, manufacturing, aviation, distribution, healthcare, mining, agriculture, consumer goods, technology, telecommunications, oil and gas, and education. An 'Other' category was included for respondents to enter sectors not provided on the survey. Of the 152 questionnaires distributed, 130 questionnaires were completed.Respondents from each industry included operational level staff (sales and service staff), functional level staff (managers from marketing, finance, human resources, and etc.), and senior level staff (directors).

\subsection{Survey}

The 91 measurement items in the survey were developed from scales with established validity and reliability and distributed among nine categories (seven mediating variables, OSA, and EC). Section one-Diffusion and Innovation-was measured with "yes" or "no" responses; Section two-Social Exchange—was measured on a five-point Likert scale ( $1=$ "Not at all" and 5= "Very extremely"); Section three - Economic Exchange-was measured with "yes" or "no" responses; Section four-Job Satisfaction-was measured on a five-point Likert scale (1= "Very Low" and 5= "Very High"); Section five- Knowledge Sharing and Satisfaction—was measured on a five-point Likert scale (1= "To no extent" and 5= "Very great extent"); Section six-Person-Organization Fit—was measured on a five-point Likert scale ( $1=$ "To no extent" and 5= "Very great extent"); Section seven-Employee Commitment—was measured on a five-point Likert scale ( $1=$ "Strongly disagree" and 5= "strongly agree"); Section eight-Organizational Strategy Awareness-was measured on a five-point Likert-type (1= "To no extent" and 5= "Very great extent"); and Section nine-Trust-was measured on a five-point Likert scale ( $1=$ "Strongly disagree" and 5= "strongly agree"). 


\section{Analysis and Results}

\subsection{Reliability}

Reliability of survey items was measured using Cronbach Alpha. The resulting statistic was 0.754; Cronbach Alpha based on standardized items was 0.827 , and number of item used for computation was 9 . Therefore, the Cronbach Alpha values represent high reliabilityamong the items used in the survey.

\subsection{Model Fit}

A raw score was developed for each of the nine categories and a structural equation model (SEM) was used to determine the validity of the theoretical model. Category variables were rescaled to a domain of $[-1,1]$ for use in the model.

The SEM had two equations (omitting coefficients and bias constants):

[1] $\mathrm{EC}=\mathrm{DOI}+\mathrm{SE}+\mathrm{EER}+\mathrm{T}+\mathrm{JS}+\mathrm{KSS}+\mathrm{POF}$

[2] $\mathrm{OSA}=\mathrm{DOI}+\mathrm{SE}+\mathrm{EER}+\mathrm{T}+\mathrm{JS}+\mathrm{KSS}+\mathrm{POF}$.

The model was fitted using Lavaan Package in R (http://lavaan.ugent.be/). SPSS was used to test the hypotheses running regression, co-variance, and partial correlation. All model fit parameters were well within acceptable bounds. The Comparative Fit Index (CFI) was 0.999, Root Mean Square Error of Approximation (RMSEA) was 0.018 and Standardized Root Mean Square Residual (SRMR) was 0.022. The model is well-fitting the data given the number of variables and data points. The results show anOSA to EC Pearson $r$ correlation of .738, $(p<.0001)$.

\subsection{Hypotheses}

To test the hypothesized mediating factors in our model, we used linear regression analysis as a substitution for Sobel Test due to the limitation of the statistical software used (SPSS). With the exception of Diffusion of Innovation and Economic Exchange, all the other mediating variables established a positive, significant correlation with Employee Commitment. Below are the results of each individual hypothesis (significant at the $p<.05$ level).

Hypothesis 1: Diffusion of innovation will mediate the positive relationship between employee organizational strategy awareness and employee commitment for organizational success. This was not supported by a partial correlation value of -.023 .

Hypothesis 2: Social exchange will mediate the positive relationship between employee organizational strategy awareness and employee commitment for organizational success. This is supported with a partial correlation value of .246.

Hypothesis 3: Economic exchange will mediate the positive relationship between employee organizational strategy awareness and employee commitment for organizational success. This was not supported by a partial correlation value of .038 .

Hypothesis 4: Trust will mediate the positive relationship between employee organizational strategy awareness and employee commitment for organizational success. This is supported with a partial correlation value of .938.

Hypothesis 5: Job satisfaction will mediate the positive relationship between employee organizational strategy awareness and employee commitment for organizational success. This is supported with a partial correlation value of .747 .

Hypothesis 6: Knowledge sharing and satisfaction will mediate the positive relationship between employee organizational strategy awareness and employee commitment for organizational success. This is supported with a partial correlation value of .678 .

Hypothesis 7: Person organization fit will mediate the positive relationship between employee organizational strategy awareness and employee commitment for organizational success. This is supported with a partial correlation value of .790 .

Hypothesis 8: Employees' organizational strategy awareness has a positive relationship with employees' commitment for organizational success. This is supported with a partial correlation value of .738 .

\section{Discussion}

This study provides support for the theoretical model proposed in Figure 1, which contains seven factors that we propose mediate between employee strategic awareness and commitment (and thus, organizational success) with the exception of the Diffusion of Innovation and Economic Exchange factorsfor which we did not find significant support. These seven factors were either suggested by previous research in the scholarly literature or 
proposed through our understanding of employee motivators. Our findings should be of interest to managers who wish to implement strategic planning that aims to enhance employees' level of organizational strategy awareness to the end of increasing employee commitment and ultimately, organizational success (profitability). The findings should also be of interest to scholars in this area who are interested in developing theory and testable models that capture the relationships among employee strategy awareness, employee commitment, and organizational success. Nonetheless, the present study is limited and should be considered preliminary. First, the present study is based on only 130 respondents across 12 sectors. This necessarily raises questions about statistical power and we would want, in a more expansive study, to collect data from more respondents in each sector and, perhaps, include more organizational sectors. We will evaluate the 'Other' category to determine additional sectors to survey. Second, we may wish to consider additional mediating factors, based on a more exhaustive review of the literature. We believe our initial review was thorough, but the possibility remains that there are additional factors to consider and add to the model. We must also examine the Diffusion of Innovation and Economic Exchange factors to understand better why these particular variables did not perform as expected. An enhanced survey instrument is in development and we expect to provide even more definitive support for the theoretical model in the near future. In the meantime, it seems apparent to us that managers wishing to enhance the relationship between employees' awareness of organizational strategy and employee commitment have at least five factors in our modelon which to focusif they wish to improve organizational success.

\section{References}

Alarcon, G. M., \& Lyons, J. B. (2011). The relationship of engagement and job satisfaction in working samples. Journal of Psychology: Interdisciplinary and Applied, 145(5), 463-480. http://dx.doi.org/10.1080/00223980.2011.584083

Altman, W. (2009). Marketing in rising economies. Engineering \& Technology, 4(11), 76-77. http://dx.doi.org/10.1049/et.2009.1120

Anderson, L. A., \& Anderson, D. (2009). Leading change. Leadership Excellence, 26(11), 3-4.

Aryee, S., Walumbwa, F. O., Zhou, Z., \& Hartnell, C. A. (2012). Transformational leadership, innovative behavior, and task performance: Test of mediation and moderation processes. Human Performance, 25(1), 1-25. http://dx.doi.org/ 10.1080/08959285.2011.631648

Asser, M. N., \& Hodges, S. (2009). Aligning culture and strategy. Of Counsel, 28(11), 13-17.

Bartek, C. (2009). Fostering innovative capacity via organizational reward systems: The case of facultycollaboration, (104). Texas: Texas A\&M University.

Canessa, N., Alemanno, F., Riva, F, Zani, A., Proverbio, A. M., Mannara, N., Perani, D., \& Cappa, S. (2012). The neural bases of social intention understanding: The role of interaction goals. PLoS ONE, 7(7), 1-11. http://dx.doi.org/ 10.1371/journal.pone.0042347

Chang, C. H., Rosen, C. C., \& Levy, P. E. (2009). The relationship between perceptions of organizational politics and employee attitudes, strain, and behavior: A meta-analytic examination. Academy of Management Journal, 52(4), 779-801. http://dx.doi.org/10.5465/AMJ.2009.43670894

Chao, C-M., Yu, C-T., Cheng, B-W., \& Chuang, P-C. (2013). Trust and commitment in relationships among medical equipment suppliers: Transaction cost and social exchange theories. Social Behavior \& Personality: An International Journal, 41(7), 1057-1069. http://dx.doi.org/10.2224/sbp.2013.41.7.1057

Chen, H. L.. (2009). Model for predicting financial performance of development and construction corporations. Journal of Construction Engineering \& Management, 135(11), 1190-1200. http://dx.doi.org/10.1061/(ASCE)CO.1943-7862.0000077

Chen, Z. (2011). The interactive effects of relationship conflict, reward, and reputation on knowledge sharing. Social Behavior \& Personality: An International Journal, 39(10), 1387-1394. http://dx.doi.org/10.2224/sbp.2011.39.10.1387

De Cuyper, N., Van der Heijden, B. I. J. M., \& De Witte, H. (2011). Associations between perceived employability, employee well being, and its contribution to organizational success: A matter of psychological contracts? International Journal of Human Resource Management, 22(7), 1486-1503. http://dx.doi.org/10.1080/09585192.2011.561962

Hakanen, J. J., Schaufeli, W. B., \& Ahola, K. (2008). The job demands-resources model: A three-year cross-lagged study of burnout, depression, commitment, and work engagement. Work \& Stress, 22(3), 224-241. http://dx.doi.org/10.1080/02678370802379432 
Jang, C-Y. (2013). Facilitating trust in virtual teams: The role of awareness. Advances in Competitiveness Research, 21(1/2), 61-77.

Jimena, J. (2009). How to create value through ethical leadership. Canadian Mining Journal, 130(2), 11.

Kexin, G. et al. (2013). Team networks and team identification: The role of leader-member exchange. Social Behavior \& Personality: An International Journal, 41(7), 1115-1123.

Liao, L-F. (2006). A learning organization perspective on knowledge-sharing behavior and firminnovation. Human Systems Management, 25(4), 227-236.

Miller, T. R., \& Amos, D. M. (2007). Cleantech innovators should be aware of certain global intellectual property issues. Intellectual Property \& Technology Law Journal, 22(5), 1-6.

Nakonezny, P. A., \& Denton, W. H. (2008). Marital relationships: A social exchange theoryperspective. American Journal of Family Therapy, 36(5), 402-412. http://dx.doi.org/10.1080/01926180701647264

Peng, J-C., \& Chiu, S-F. (2010). An integrative model linking feedback environment andorganizational citizenship behavior. Journal of Social Psychology, 150(6), 582-607. http://dx.doi.org/10.1080/00224540903365455

Sharma, D., Borna, S., \& Stearns, J. M. (2009). An investigation of the effects of organizationalethical values on employeecommitment and performance: Examining the moderating role of perceived fairness. Journal of Business Ethics, 89(2), 251-260. http://dx.doi.org/10.1007/s10551-008-9997-4

Shin, J., Taylor, M. S., \& Seo, M. G. (2012). Resources for change: The relationships of organizational inducements andpsychological resilience to employees' attitudes and behaviors toward organizational change. Academy of Management Journal, 55(3), 727-748. http://dx.doi.org/10.5465/amj.2010.0325

Taris, T. W., \& Schreurs, P. J. G. (2009). Well-being and organizational performance: An organizational-level test of the happy-productive worker hypothesis. Work \& Stress, 23(2), 120-136. http://dx.doi.org/10.1080/02678370903072555

Tyler, B. B., \& Gnyawali, D. R. (2009). Managerial collective cognitions: An examination of similarities and differences of cultural orientations. Journal of Management Studies, 46(1), 93-126. http://dx.doi.org/10.1111/j.1467-6486.2008.00795.x

Wu, W-L. (2013). To share knowledge or not: Dependence on knowledge-sharing satisfaction. Social Behavior \& Personality: An International Journal, 41(1), 47-58. http://dx.doi.org/10.2224/sbp.2013.41.1.47

Zhu, Y. (2012). Social exchange relationship, economic exchange relationship, in-role behavior: The mediating effects of job satisfaction. Asian Social Science, 8(8), 194-199. http://dx.doi.org/10.5539/ass.v8n8p194

\section{Copyrights}

Copyright for this article is retained by the author(s), with first publication rights granted to the journal. This is an open-access article distributed under the terms and conditions of the Creative Commons Attribution license (http://creativecommons.org/licenses/by/3.0/). 